\section{Extreme thinness in models mobilizes eating disorders' researchers and specialists}

\author{
A magreza extrema \\ em modelos mobiliza \\ pesquisadores e \\ especialistas em \\ distúrbios da \\ alimentação
}

The tragic recent deaths of two young Brazilian models last November caused feelings of sadness and great sorrow, and raised many relevant questions such as 'Can the desire to be thin cause an eating disorder?', 'What kind of link is there between the fashion industry and the etiology of eating disorders in modern society?', and 'What can be done to prevent such potentially lethal illnesses?'.

Researches in this field show that eating disorders are caused by a combination of genetic, neurochemical, psychodevelopmental and sociocultural factors. ${ }^{1}$ One of the sociocultural factors is the extreme thin ideal of beauty in our westernized culture: there is scientific evidence that models' images, as presented in any issue of a women's magazine, may have a detrimental effect on women, particularly those who are more vulnerable. ${ }^{2}$

It is well known that eating disorders, in particular anorexia nervosa and bulimia nervosa, have a higher incidence in female adolescence. ${ }^{3}$ Some occupations such as fashion models, dancers, athletes (e.g. jockeys), in which weight and/or body shape are very important, are also at a higher risk range. Therefore, being an adolescent fashion model means to be exposed to many risk factors that when associated with other vulnerabilities such as genetic or familial characteristics can precipitate the onset of an eating disorder. For this reason, this group should be a target for close monitoring, and parents and caretakers should be aware of the exposure of their child to such potentials risks. In addition, model agents and sports coaches should also be concerned about these health issues and guarantee psychological and nutritional support to the professionals at their care.

However, most individuals presenting eating disorders are not a part of any special occupational risk group; they are young people, and most of them live in societies where the modern thin ideal of beauty is an overemphasized value that causes many false beliefs and has false meanings such as "success", "power", "competence", "happiness" and "wealth". Therefore, it seems of even greater relevance to take actions towards monitoring, as a matter of public health, what is portrayed by the media and women's magazines as the ideal of beauty. Such thin standards of body weight and shape may be contributing to the development of eating disorders in vulnerable subjects, as these standards are unattainable and unhealthy for the majority of young women. Health policy makers should be aware of this issue and start to develop effective measures to deal with this environmental risk.

Researchers and specialists on eating disorders have the responsibility to clarify these aspects to segments of society that must be involved in preventive actions. Some initial steps towards change were already taken. Last August, at a major fashion show in Spain, excessively thin models, with body mass index below $18 \mathrm{~kg} / \mathrm{m}^{2}$, were banned from the catwalk. Other important international initiatives were taken by the Academy for Eating Disorders (AED) - an international organization for eating disorder treatment, research and education of professionals - that published 'The Worldwide Charter for Action on Eating Disorders', ${ }^{4}$ a document that provides people with 
eating disorders, their families and loved ones with a list of their basic rights and reasonable expectation regarding eating disorder treatment and services. We urge Brazilian health care authorities to formally adopt the World Wide Charter. In addition, the AED published a media release, last October, calling for a ban of underweight models.

In Brazil, the eating disorders services mainly at university centers, with the support of the Brazilian Psychiatry Association (Associação Brasileira de Psiquiatria) and the AED, wrote a public communication addressed to the Brazilian community last November. ${ }^{5}$ It commented on two young models deaths and stated that an overemphasis on an extreme thin ideal can strongly contribute to the development and perpetuation of inadequate eating behaviors in susceptible individuals. It also reported the necessity of debating the issue with a variety of our society segments such as health professionals, fashion industry official representatives, legal and governmental authorities, parents and teachers associations, to collaboratively establish a real impact proposal towards protecting the health of young people who might be at risk.

Tatiana Moya Obesity and Eating Disorders Group (GOTA), Instituto Estadual de Diabetes e Endocrinologia (IEDE), Instituto de Psiquiatria da Universidade do Brasil (IPUB), Universidade Federal do Rio de Janeiro (UFRJ), Rio de Janeiro (RJ), Brazil

Angélica $M$ Claudino Eating Disorders Program (PROATA), Escola Paulista de Medicina, Universidade Federal de São Paulo (UNIFESP), São Paulo (SP), Brazil

Eric $F$ van Furth Academy for Eating Disorders (AED), President Center for Eating Disorders Ursula, Leidschendam, the Netherlands Department of Psychiatry, Leiden University, the Netherlands

\section{References}

1. Becker AE, Grinspoon SK, Klibanski A, Herzog DB. Eating disorders. N Engl J Med. 1999;340(14):1092-8.

2. Pinhas L, Toner BB, Ali A, Garfinkel PE, Stuckless N. The effects of the ideal of female beauty on mood and body satisfaction. Int J Eat Disord. 1999;25(2):223-6.

3. Hoek HW. Incidence, prevalence and mortality of anorexia nervosa and other eating disorders. Curr Opin Psychiatry. 2006;19(4):389-94.

4. Academy for Eating Disorders - AED. Worldwide Charter for Action on Eating Disorders. Rights and expectations for people with eating disorders and their families. [cited 2006 Nov 28] Available at: http://www.aedweb.org/documents/WWCharter3.pdf.

5. Associação Brasileira de Psiquiatria - ABP. Casos de transtornos alimentares preocupam identidades. Notícias Institucionais. [updated 2006 Nov 28, cited 2006 Nov 29] Available at: http:// www.abpbrasil.org.br/noticias/exibNoticia/?not $=368$
Financing: None

Conflict of interests: None 